\title{
LRRK2 G2385R and R1628P Mutations Are Associated with an Increased Risk of Parkinson's Disease in the Malaysian Population
}

\author{
Aroma Agape Gopalai, ${ }^{1}$ Shen-Yang Lim, ${ }^{2}$ Jing Yi Chua, ${ }^{1}$ Shelisa Tey, ${ }^{1}$ \\ Thien Thien Lim, ${ }^{3}$ Norlinah Mohamed Ibrahim, ${ }^{4}$ Ai Huey Tan, ${ }^{2}$ Gaik Bee Eow, ${ }^{3}$ \\ Zariah Abdul Aziz, ${ }^{5}$ Santhi Datuk Puvanarajah, ${ }^{6}$ Shanthi Viswanathan, ${ }^{6}$ Irene Looi, ${ }^{7}$ \\ Soo Kun Lim, ${ }^{2}$ Li Ping Tan, ${ }^{2}$ Yip Boon Chong, ${ }^{2}$ Chong Tin Tan, ${ }^{2}$ Yi Zhao, ${ }^{8}$ \\ E. K. Tan, ${ }^{8}$ and Azlina Ahmad-Annuar ${ }^{1}$ \\ ${ }^{1}$ Department of Biomedical Science, Faculty of Medicine, University of Malaya, 50603 Kuala Lumpur, Malaysia \\ ${ }^{2}$ Divisions of Neurology and Nephrology, Department of Medicine, Faculty of Medicine, University of Malaya, \\ 50603 Kuala Lumpur, Malaysia \\ ${ }^{3}$ Department of Neurology, Hospital Pulau Pinang, 10990 Penang, Malaysia \\ ${ }^{4}$ Division of Neurology, Department of Medicine, Hospital Universiti Kebangsaan Malaysia, 56000 Kuala Lumpur, Malaysia \\ ${ }^{5}$ Division of Neurology, Department of Medicine, Hospital Sultanah Nur Zahirah, 20400 Kuala Terengganu, Malaysia \\ ${ }^{6}$ Department of Neurology, Hospital Kuala Lumpur, 50586 Kuala Lumpur, Malaysia \\ ${ }^{7}$ Department of Medicine, Hospital Seberang Jaya, 13700 Penang, Malaysia \\ ${ }^{8}$ Department of Clinical Research and Neurology, Singapore General Hospital, Singapore 169608
}

Correspondence should be addressed to Azlina Ahmad-Annuar; azlina.ahmadannuar@gmail.com

Received 23 May 2014; Accepted 24 July 2014; Published 28 August 2014

Academic Editor: Hiroyuki Tomiyama

Copyright ( 2014 Aroma Agape Gopalai et al. This is an open access article distributed under the Creative Commons Attribution License, which permits unrestricted use, distribution, and reproduction in any medium, provided the original work is properly cited.

The LRRK2 gene has been associated with both familial and sporadic forms of Parkinson's disease (PD). The G2019S variant is commonly found in North African Arab and Caucasian PD patients, but this locus is monomorphic in Asians. The G2385R and R1628P variants are associated with a higher risk of developing PD in certain Asian populations but have not been studied in the Malaysian population. Therefore, we screened the G2385R and R1628P variants in 1,202 Malaysian subjects consisting of 695 cases and 507 controls. The G2385R and R1628P variants were associated with a 2.2-fold $(P=0.019)$ and 1.2-fold $(P=0.054)$ increased risk of PD, respectively. Our data concur with other reported findings in Chinese, Taiwanese, Singaporean, and Korean studies.

\section{Introduction}

Parkinson's disease (PD) is an age-related illness, and, as populations age, the proportion of people with this neurodegenerative disease will continue to rise. It is projected that, by the year 2030, 9.3 million individuals above the age of 50 will suffer from PD and these cases will be concentrated outside the western world [1]. Studies have implicated exposure to environmental toxins and trauma as aetiological factors for $\mathrm{PD}$ [2]. Genetic variations also play a role, especially in cases where there is a family history of $\mathrm{PD}$, which account for around $10-20 \%$ of all PD cases [3]. However, studies have shown that even late-onset sporadic PD may also have a genetic contribution [4].

One of the genes commonly implicated in both familial and sporadic PD is the leucine-rich repeat kinase 2 (LRRK2) gene. Several variants of LRRK2 such as R1441C, G2019S, and I2020T have been well established as risk factors for $\mathrm{PD}$ [3]. Interestingly, there appear to be population-specific variants in LRRK2; for example, the G2019S variant is prevalent among the Ashkenazi Jews and North African Arabs 
TABLE 1: Summary of the genotyping data.

\begin{tabular}{lccc}
\hline SNP & PD (MAF) & Controls (MAF) & OR (95\% confidence interval) \\
\hline Wild type (G) & & G2385R (c.7153G>A), rs34778348 & OR 2.22 (1.15-4.29) \\
Variant (A) & $1354(0.974)$ & $1002(0.999)$ & $P=0.019$ \\
\hline & $36(0.026)$ & $12(0.001)$ & OR 1.23 (1.039-1.448) \\
Wild type (G) & $1347(0.969)$ & R1628P (c.4883G>C), rs33949390 & $P=0.054$ \\
Variant (C) & $43(0.031)$ & $18(0.018)$ & $P$. \\
\hline
\end{tabular}

TABLE 2: Summary of published Asian data on G2385R and R1628P.

\begin{tabular}{|c|c|c|c|}
\hline Study & Asian country & Sample size & Results \\
\hline \multicolumn{4}{|c|}{ G2385R (c.7153G>A), rs34778348 } \\
\hline Di Fonzo et al., 2006 [9] & Taiwan & $608 \mathrm{PD}, 373$ controls & OR $2.24(P=0.004)$ \\
\hline Fung etal., 2006 [20] & Taiwan & 305 PD, 176 controls & OR $17.00(P=0.0002)$ \\
\hline Farrer et al., 2007 [21] & Taiwan & $410 \mathrm{PD}, 335$ controls & OR $2.24(P=0.014)$ \\
\hline Tan et al., 2007 [14] & Singapore & 495 PD, 494 controls & OR $2.14(P=0.014)$ \\
\hline Tan et al., 2007 [16] & $\begin{array}{l}\text { Non-Chinese Asian (Malays and } \\
\text { Indians) }\end{array}$ & $\begin{array}{l}98 \mathrm{PD}, 173 \text { controls } \\
66 \mathrm{PD}, 133 \text { controls }\end{array}$ & $\begin{array}{c}\text { Malays } \\
\text { OR } 1.78(P=0.3) \\
\text { Indians-monomorphic }\end{array}$ \\
\hline An et al., 2008 [11] & Mainland China & $600 \mathrm{PD}, 334$ controls & OR $3.94(P<0.01)$ \\
\hline Funayama et al., 2007 [10] & Japan & $448 \mathrm{PD}, 457$ controls & OR $2.60\left(P=1.24 \times 10^{-4}\right)$ \\
\hline Zabetian et al., 2009 [7] & Japan & $601 \mathrm{PD}, 1,628$ controls & OR $1.96(P<0.001)$ \\
\hline Miyake et al., 2010 [22] & Japan & 229 PD, 358 controls & OR 2.06 \\
\hline Kim et al., 2010 [12] & Korea & $\begin{array}{l}923 \text { PD, } 422 \text { controls } \\
119 \text { YOPD } \\
814 \text { LOPD }\end{array}$ & $\begin{array}{c}\text { Combined } \\
\text { OR 1.83 }(P=0.017) \\
\text { YOPD } \\
\text { OR 2.28 }(P=0.098) \\
\text { LOPD } \\
\text { OR 1.81 }(P=0.022)\end{array}$ \\
\hline Ross et al., 2011 [19] & Asian & $\begin{array}{l}\text { Taiwanese } \\
369 \text { PD, } 300 \text { controls } \\
\text { Korean } \\
844 \text { PD, } 587 \text { controls } \\
\text { Japanese } \\
173 \text { PD, } 95 \text { controls } \\
\text { Combined } \\
\text { 1,386 PD, } 982 \text { controls }\end{array}$ & $\begin{array}{c}\text { OR } 1.62 \\
{ }^{*} P \text { value not stated } \\
\text { OR } 1.87 \\
{ }^{*} P \text { value not stated } \\
\text { OR } 1.44 \\
{ }^{*} P \text { value not stated } \\
\text { OR } 1.73(P=0.0026)\end{array}$ \\
\hline Current study & Malaysia & 695 PD, 507 controls & OR $2.22(P=0.019)$ \\
\hline \multicolumn{4}{|c|}{ R1628P (c.4883G>C), rs33949390 } \\
\hline Mata et al., 2005 [15] & Europe, Asia, and North America & $\begin{array}{l}100 \text { PD probands with family } \\
\text { history of parkinsonism, } \\
300 \text { controls }\end{array}$ & MAF 0.01 \\
\hline Lu et al., 2008 [18] & Taiwan & $834 \mathrm{PD}, 543$ controls & OR $2.13(P=0.004)$ \\
\hline Tan et al., 2008 [16] & Singapore & 246 PD, 243 controls & OR $2.5(P=0.046)$ \\
\hline Tan et al., 2008 [23] & $\begin{array}{l}\text { Non-Chinese Asian (Malays and } \\
\text { Indians) }\end{array}$ & $\begin{array}{l}132 \mathrm{PD}, 160 \text { controls } \\
60 \mathrm{PD}, 105 \text { controls }\end{array}$ & $\begin{array}{l}\text { OR } 0.61(P=0.600) \\
\text { Indians-monomorphic }\end{array}$ \\
\hline Ross et al., 2008 [13] & Taiwan, Singapore & $\begin{array}{l}\text { Wu RM } \\
484 \text { PD, } 341 \text { controls } \\
\text { Wu YR } \\
345 \text { PD, } 316 \text { controls } \\
\text { EK Tan } \\
250 \text { PD, } 250 \text { controls } \\
\text { Combined } \\
1079 \text { PD, } 907 \text { controls }\end{array}$ & $\begin{array}{l}\text { OR } 2.15(P=0.025) \\
\text { OR } 1.39(P=0.179) \\
\text { OR } 2.20(P=0.163) \\
\text { OR } 1.84(P=0.006)\end{array}$ \\
\hline Zabetian et al., 2009 [7] & Japanese & $631 \mathrm{PD}, 320$ controls & Monomorphic \\
\hline Yu et al., 2009 [24] & Mainland China & 328 PD, 300 controls & OR $2.68(P<0.05)$ \\
\hline Zhang et al., 2009 [25] & Mainland China & $600 \mathrm{PD}, 459$ controls & OR $3.14(P<0.01)$ \\
\hline Kim et al., 2010 [12] & Korea & $384 \mathrm{PD}, 384$ controls & OR $2.98(P=0.32)$ \\
\hline Pulkes et al., 2011 [17] & Thai & 154 PD, 156 controls & OR $3.25(P=0.021)$ \\
\hline
\end{tabular}


TABLE 2: Continued.

\begin{tabular}{|c|c|c|c|}
\hline Study & Asian country & Sample size & Results \\
\hline \multirow{4}{*}{ Ross et al., 2011 [19] } & \multirow{4}{*}{ Asian } & $\begin{array}{l}\text { Taiwanese } \\
\text { (369 PD, } 300 \text { controls) }\end{array}$ & OR $0.56(P=0.054)$ \\
\hline & & $\begin{array}{l}\text { Korean } \\
\text { (844 PD, } 587 \text { controls) }\end{array}$ & OR $2.47(P=0.42)$ \\
\hline & & $\begin{array}{l}\text { Japanese } \\
\text { (173 PD, } 95 \text { controls) }\end{array}$ & Monomorphic \\
\hline & & $\begin{array}{l}\text { Combined } \\
\text { (1,386 PD, } 982 \text { controls) }\end{array}$ & OR $0.62(P=0.087)$ \\
\hline Current study & Malaysian & 695 PD, 507 controls & OR $1.23(P=0.054)$ \\
\hline
\end{tabular}

(occurring in approximately $20 \%$ and $40 \%$ of PD patients in these groups, respectively [5]) but is absent in Asian populations (Chinese, Indian, Korean, and Japanese) [6, 7]. In Asian (Chinese, Taiwanese, Singaporean, and Japanese) populations, the G2385R variant is a more established risk variant but conversely is not found in Caucasian or Jewish patients with PD [8-12]. The R1628P is another common risk variant in Asian PD populations (Chinese, Taiwanese, and Singaporean) [13].

Given the lack of data regarding how these variants contribute to PD in Malaysian patients, we sought to investigate the prevalence of G2385R and R1628P in a Malaysian PD cohort. We found that G2385R was significantly associated with $\mathrm{PD}$ and $\mathrm{R} 1628 \mathrm{P}$ showed a trend towards being a risk factor.

\section{Methodology}

A total of 1,202 subjects participated in this study. Six hundred and ninety-five PD patients were diagnosed by neurologists based on the United Kingdom PD Brain Bank Criteria and 507 controls who did not suffer from any neurological or movement disorders were recruited. Ethics approval and written consent from subjects were obtained. DNA was extracted from lymphocytes that were obtained from venous blood using the phenol-chloroform method. The G2385R (rs34778348) and R1628P (rs33949390) genotyping was done by Taqman allelic discrimination assay on a 7500 Fast RealTime PCR machine. A subset of 20 individuals was sequenced to determine the error rate. The allele and genotype frequencies in PD cases and controls were compared with Fisher's exact test. Statistical analyses were performed using an opensource software (OpenEpi).

\section{Results and Discussion}

The mean age at PD diagnosis was $57.4 \pm 11.8$ years and the mean age of controls was $59.3 \pm 9.4$ years. Sixty percent of PD patients and $51 \%$ of controls were male. Results of the G2385R and R1628P genotyping are summarised in Table 1 . The error rate of the assay was $0 \%$ in the subset of 20 individuals. Fiftyfive patients $(7.9 \%)$ had early-onset PD (onset $<40$ years). Four patients were compound heterozygous for G2385R and R1628P; two of these patients had a family history of PD and developed PD before the age of 50, while the other two patients had no family history and had a later age of onset $(>55)$.

The G2385R variant was associated with $P D$, with an odds ratio (OR) of $2.22(P=0.019)$, while the $\mathrm{R} 1628 \mathrm{P}$ variant had an OR of 1.23 with a trend towards significance $(P=0.054)$. Interestingly, the G2385R mutation was present in control subjects as well (MAF $=0.001)$, although it was less frequently present than in the PD cohort (MAF $=0.026)$.

Our findings are in keeping with other published reports on G2385R, where this variant is associated with an increased risk of developing PD by approximately twofold (Chinese, Taiwanese, Singaporean, and Japanese populations) (Table 2). The G2385R variant is located within the WD40 domain of $L R R K 2$, which is responsible for a variety of functions including signal transduction, pre-mRNA processing, and cytoskeleton assembly, and cells carrying the G2385R variant are more susceptible to oxidative stress and apoptosis [14].

The R1628P variant was first identified by Mata et al. [15]. Subsequently, Ross et al. reported this variant to be the second common genetic risk factor for PD in the ethnic Chinese (Taiwanese and Singaporean) population, with an OR of $1.84(P=0.006)[13]$. Other independent studies carried out by Tan et al., Pulkes et al., and Lu et al. in Singapore, Thailand, and China showed a similar trend with OR values of $2.5,3.3$, and 2.1, respectively [16-18]. However, this was not observed in a Japanese cohort where the locus was found to be monomorphic [7]. This mutation alters a highly conserved amino residue within the "COR" domain of the LRRK2 protein [18]. The substitution of a highly basic polar arginine $(\mathrm{R})$ with a neutral nonpolar proline $(\mathrm{P})$ is likely to cause a conformational change in the protein secondary structure, thus altering the function of the protein. We note however that a recent multicentre study by Ross et al. involving 1386 Asian PD cases and 982 Asian controls did not find an association with R1628P (OR 0.62, 95\% CI 0.36$1.07, P=0.087$ ) [19]. Whilst the findings in their Japanese and Korean subsets were consistent with previously published data, their Taiwanese cohort did not show a risk association, but rather a trend in the opposite direction (i.e., protective, with an OR of $0.56,95 \%$ CI $0.32-1.01, P=0.054$ ).

In conclusion, our data concur with other reports in the Chinese, Taiwanese, Singaporean, and Korean populations. The G2385R variant is significantly associated with an increased risk of developing PD, while the R1628P variant is predicted to have a more modest effect. These data together with others can lead to a better understanding of the 
pathogenetic pathways leading to cell dysfunction and death in $\mathrm{PD}$, with the ultimate hope that more specific drugs can be developed to treat this disabling disease.

\section{Conflict of Interests}

The authors declare that they have no conflict of interests regarding the publication of this paper.

\section{Acknowledgments}

This study was supported by an FRGS Grant (FP017-2013B, awarded to AAA) and a Malaysian Ministry of Higher Education Grant for High Impact Research (HIR) (E000033, awarded to SYL).

\section{References}

[1] E. R. Dorsey, R. Constantinescu, J. P. Thompson et al., "Projected number of people with Parkinson disease in the most populous nations, 2005 through 2030," Neurology, vol. 68, no. 5, pp. 384-386, 2007.

[2] P. Lee, Y. Bordelon, J. Bronstein, and B. Ritz, “Traumatic brain injury, paraquat exposure, and their relationship to Parkinson disease," Neurology, vol. 79, no. 20, pp. 2061-2066, 2012.

[3] L. M. Bekris, F. M. Ignacio, and C. P. Zabetian, "The genetics of Parkinson disease," Journal of Geriatric Psychiatry and Neurology, vol. 23, no. 4, pp. 228-242, 2010.

[4] W. Satake, Y. Nakabayashi, I. Mizuta et al., "Genome-wide association study identifies common variants at four loci as genetic risk factors for Parkinson's disease," Nature Genetics, vol. 41, no. 12, pp. 1303-1307, 2009.

[5] L. J. Ozelius, G. Senthil, R. Saunders-Pullman et al., "LRRK2 G2019S as a cause of Parkinson's disease in Ashkenazi Jews," New England Journal of Medicine, vol. 354, no. 4, pp. 424-425, 2006.

[6] E. K. Tan, H. Shen, L. C. S. Tan et al., “The G2019S LRRK2 mutation is uncommon in an Asian cohort of Parkinson's disease patients," Neuroscience Letters, vol. 384, no. 3, pp. 327-329, 2005.

[7] C. P. Zabetian, M. Yamamoto, A. N. Lopez et al., "LRRK2 mutations and risk variants in Japanese patients with Parkinson's disease," Movement Disorders, vol. 24, no. 7, pp. 1034-1041, 2009.

[8] M. Toft, K. Haugarvoll, O. A. Ross, M. J. Farrer, and J. O. Aasly, "LRRK2 and Parkinson's disease in Norway," Acta Neurologica Scandinavica, vol. 115, no. 187, pp. 72-75, 2007.

[9] A. Di Fonzo, Y. H. Wu-Chou, C. S. Lu et al., "A common missense variant in the LRRK2 gene, Gly2385Arg, associated with Parkinson's disease risk in Taiwan," Neurogenetics, vol. 7, no. 3, pp. 133-138, 2006.

[10] M. Funayama, Y. Li, H. Tomiyama et al., "Leucine-rich repeat kinase 2 G2385R variant is a risk factor for Parkinson disease in Asian population," NeuroReport, vol. 18, no. 3, pp. 273-275, 2007.

[11] X.-K. An, R. Peng, T. Li et al., "LRRK2 Gly2385Arg variant is a risk factor of Parkinson's disease among Han-Chinese from mainland China," European Journal of Neurology, vol. 15, no. 3 , pp. 301-305, 2008.

[12] J. M. Kim, J. Y. Lee, H. J. Kim et al., “The LRRK2 G2385R variant is a risk factor for sporadic Parkinson's disease in the Korean population," Parkinsonism and Related Disorders, vol. 16, no. 2, pp. 85-88, 2010.

[13] O. A. Ross, Y. Wu, M. Lee et al., "Analysis of Lrrk2 R1628P as a risk factor for Parkinson's disease," Annals of Neurology, vol. 64, no. 1, pp. 88-92, 2008.

[14] E. K. Tan, Y. Zhao, L. Skipper et al., “The LRRK2 Gly2385Arg variant is associated with Parkinson's disease: genetic and functional evidence," Human Genetics, vol. 120, no. 6, pp. 857863, 2007.

[15] I. F. Mata, J. M. Kachergus, J. P. Taylor et al., "Lrrk2 pathogenic substitutions in Parkinson's disease," Neurogenetics, vol. 6, no. 4, pp. 171-177, 2005.

[16] E. K. Tan, L. C. Tan, H. Q. Lim et al., "LRRK2 R1628P increases risk of Parkinson's disease: replication evidence," Human Genetics, vol. 124, no. 3, pp. 287-288, 2008.

[17] T. Pulkes, C. Papsing, S. Mahasirimongkol, M. Busabaratana, K. Kulkantrakorn, and S. Tiamkao, "Frequencies of LRRK2 variants in Thai patients with Parkinson's disease: evidence for an R1628P founder," Journal of Neurology, Neurosurgery and Psychiatry, vol. 82, no. 10, pp. 1179-1180, 2011.

[18] C. Lu, Y. Wu-Chou, M. Van Doeselaar et al., "The LRRK2 Arg1628Pro variant is a risk factor for Parkinson's disease in the Chinese population," Neurogenetics, vol. 9, no. 4, pp. 271-276, 2008.

[19] O. A. Ross, A. I. Soto-Ortolaza, M. J. Heckman et al., "Association of LRRK2 exonic variants with susceptibility to Parkinsons disease: a casecontrol study," Lancet Neurology, vol. 10, pp. 898908, 2011.

[20] H. C. Fung, C. M. Chen, J. Hardy, A. B. Singleton, and Y. R. Wu, "A common genetic factor for Parkinson disease in ethnic Chinese population in Taiwan," BMC Neurology, vol. 6, article 47, 2006.

[21] M. J. Farrer, J. T. Stone, C. Lin et al., "Lrrk2 G2385R is an ancestral risk factor for Parkinson's disease in Asia," Parkinsonism and Related Disorders, vol. 13, no. 2, pp. 89-92, 2007.

[22] Y. Miyake, Y. Tsuboi, M. Koyanagi et al., "LRRK2 Gly2385Arg polymorphism, cigarette smoking, and risk of sporadic Parkinson's disease: a case-control study in Japan," Journal of the Neurological Sciences, vol. 297, no. 1-2, pp. 15-18, 2010.

[23] E. Tan, M. Tang, L. C. Tan et al., "Lrrk2 R1628P in non-Chinese Asian races," Annals of Neurology, vol. 64, no. 4, pp. 472-473, 2008.

[24] L. Yu, F. Hu, X. Zou et al., "LRRK2 R1628P contributes to Parkinson's disease susceptibility in Chinese Han populations from mainland China," Brain Research, vol. 1296, pp. 113-116, 2009.

[25] Z. Zhang, J. Burgunder, X. An et al., "LRRK2 R1628P variant is a risk factor of Parkinson's disease among Han-Chinese from mainland China," Movement Disorders, vol. 24, no. 13, pp. $1902-$ 1905, 2009. 

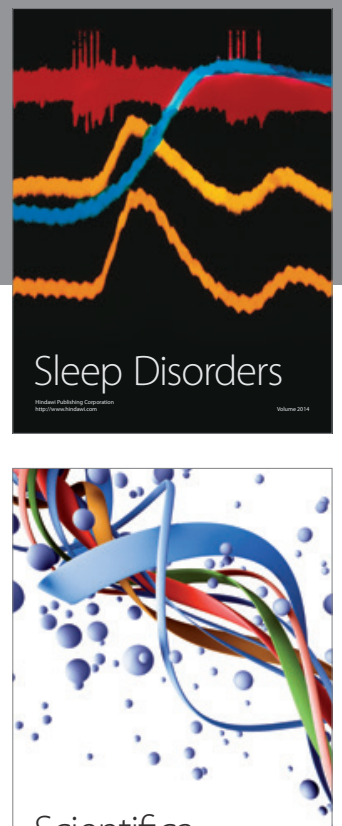

Scientifica
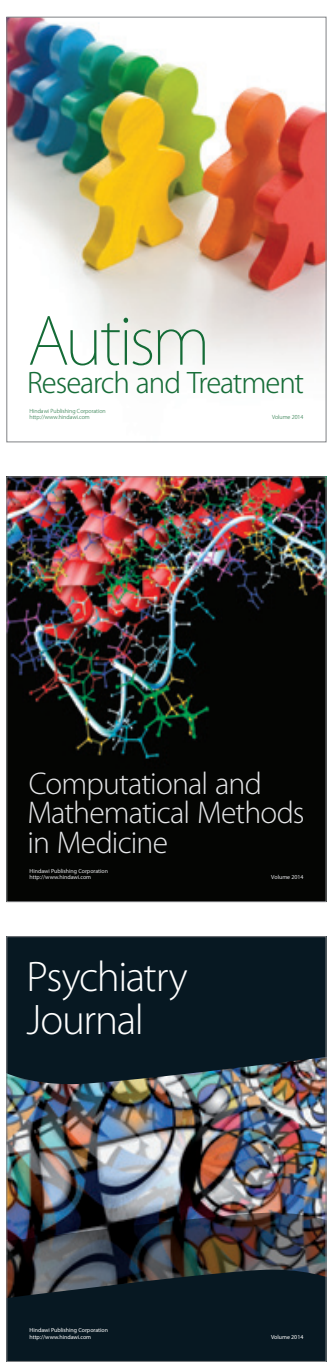
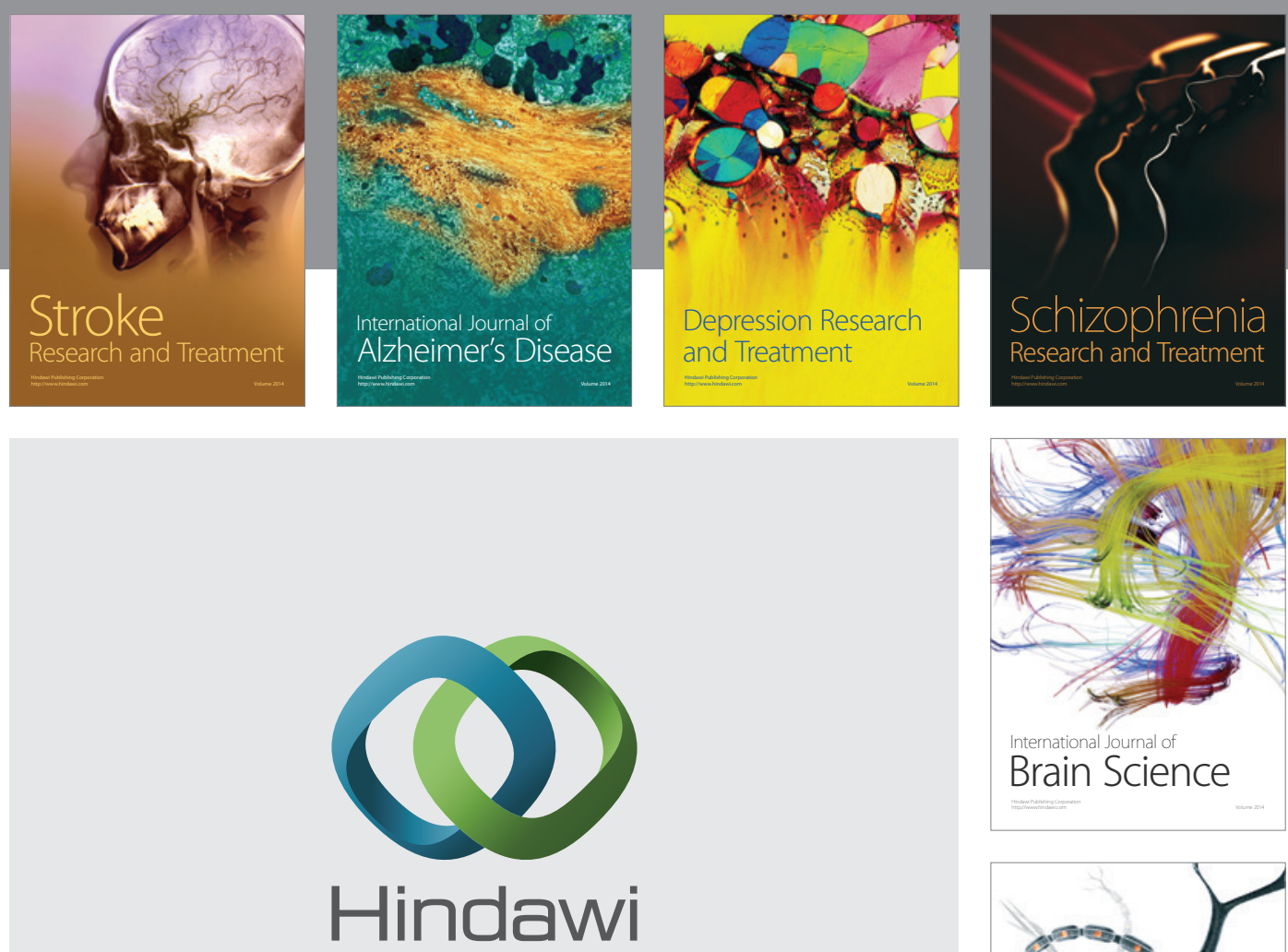

Submit your manuscripts at

http://www.hindawi.com
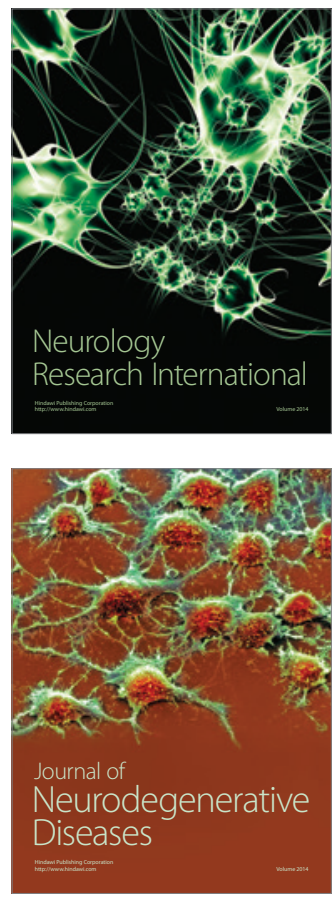

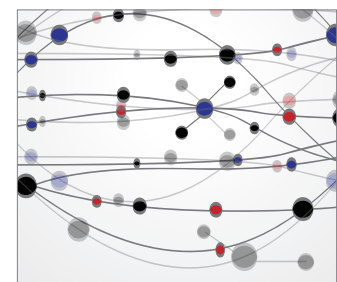

The Scientific World Journal
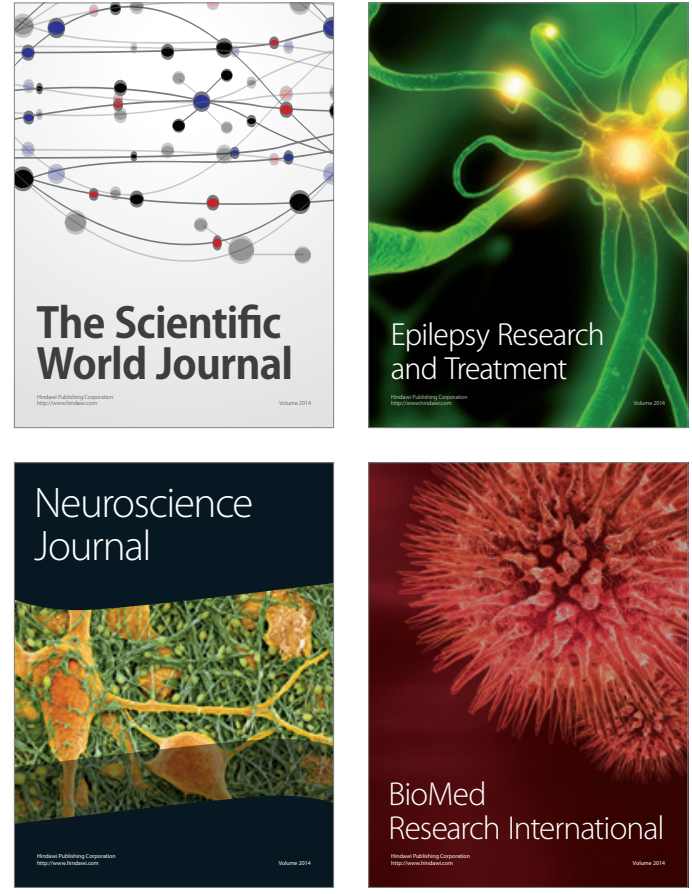

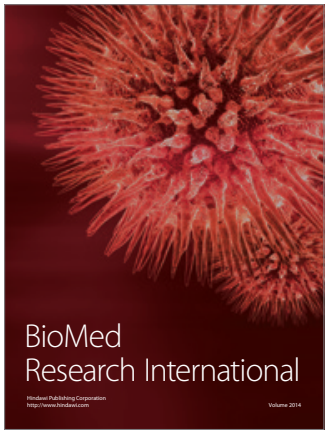

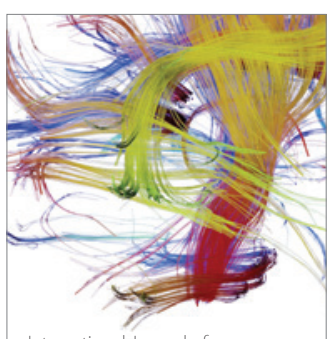

Brain Science

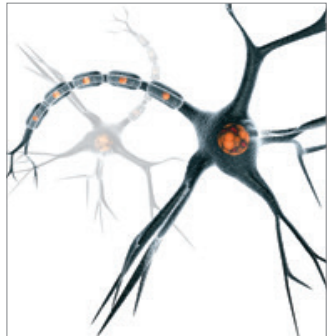

Neural Plasticity
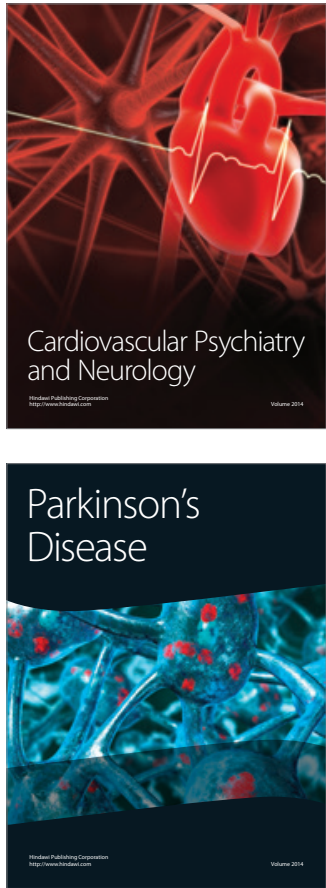